\title{
HSulf-2, an extracellular endoglucosamine-6-sulfatase, selectively mobilizes heparin-bound growth factors and chemokines: effects on VEGF, FGF-I, and SDF-I
}

\author{
Kenji Uchimura ${ }^{1}$, Megumi Morimoto-Tomita ${ }^{1}$, Annette Bistrup ${ }^{2}$, Jessica Li ${ }^{1}$, \\ Malcolm Lyon ${ }^{3}$, John Gallagher ${ }^{3}$, Zena Werb ${ }^{1}$ and Steven D Rosen*1
}

Address: ${ }^{1}$ Department of Anatomy and the UCSF Comprehensive Cancer Center, University of California, San Francisco, CA 94143-0452, USA, ${ }^{2}$ Thios Pharmaceuticals, 5980 Horton Street, Emeryville, CA 94608, USA and ${ }^{3}$ Department of Medical Oncology, University of Manchester, Paterson Institute for Cancer Research, Manchester, UK

Email: Kenji Uchimura - ihcu@itsa.ucsf.edu; Megumi Morimoto-Tomita - megumi@itsa.ucsf.edu; Annette Bistrup - abistrup@sbcglobal.net; Jessica Li - jessli@stanford.edu; Malcolm Lyon - MLyon@PICR.man.ac.uk; John Gallagher - JGallagher@PICR.man.ac.uk;

Zena Werb - zena@itsa.ucsf.edu; Steven D Rosen* - sdr@itsa.ucsf.edu

* Corresponding author

Published: 17 January 2006

BMC Biochemistry 2006, 7:2 doi:10.1186/147/-209/-7-2

This article is available from: http://www.biomedcentral.com//47I-209|/7/2

(C) 2006 Uchimura et al; licensee BioMed Central Ltd.

This is an Open Access article distributed under the terms of the Creative Commons Attribution License (http://creativecommons.org/licenses/by/2.0), which permits unrestricted use, distribution, and reproduction in any medium, provided the original work is properly cited.

\begin{abstract}
Background: Heparin/heparan sulfate (HS) proteoglycans are found in the extracellular matrix (ECM) and on the cell surface. A considerable body of evidence has established that heparin and heparan sulfate proteoglycans (HSPGs) interact with numerous protein ligands including fibroblast growth factors, vascular endothelial growth factor (VEGF), cytokines, and chemokines. These interactions are highly dependent upon the pattern of sulfation modifications within the glycosaminoglycan chains. We previously cloned a cDNA encoding a novel human endosulfatase, HSulf-2, which removes 6-O-sulfate groups on glucosamine from subregions of intact heparin. Here, we have employed both recombinant HSulf-2 and the native enzyme from conditioned medium of the MCF-7-breast carcinoma cell line. To determine whether HSulf-2 modulates the interactions between heparin-binding factors and heparin, we developed an ELISA, in which soluble factors were allowed to bind to immobilized heparin.
\end{abstract}

Results: Our results show that the binding of VEGF, FGF-I, and certain chemokines (SDF-I and SLC) to immobilized heparin was abolished or greatly diminished by pre-treating the heparin with HSulf-2. Furthermore, HSulf-2 released these soluble proteins from their association with heparin. Native Sulf-2 from MCF-7 cells reproduced all of these activities.

Conclusion: Our results validate Sulf- 2 as a new tool for deciphering the sulfation requirements in the interaction of protein ligands with heparin/HSPGs and expand the range of potential biological activities of this enzyme.

\section{Background}

Heparan sulfate proteoglycans (HSPGs) abundantly exist in the ECM and on the cell surface of most cells [1,2]. They are composed of a restricted set of core proteins to which one or more glycosaminoglycan chains (GAG) are covalently attached. It is established that HSPGs are involved 
in a wide range of biological functions through their ability to bind to and modify the activities of a diverse repertoire of ligands including growth factors, morphogens, cytokines, chemokines, proteases, lipases, matrix proteins, and cell adhesion molecules [3-6]. Heparan sulfate (HS) chains and heparins (chemical analogues of these chains) consist of repeating disaccharide units of glucuronic/iduronic acid and glucosamine that are subject to a complex set of modifications involving deacetylation, epimerization, and sulfation. Four different sites of sulfation are found in heparin/HS: the $\mathrm{N}-, 3-\mathrm{O}$, and 6-O positions of glucosamine and the 2-O position of the iduronic acid residue. Heparin is highly-sulfated throughout the polymer chain whereas in HS these modifications are concentrated mainly in the S-domains, which consist of contiguous clusters of $\mathrm{N}$-sulfated disaccharide units variably sulfated at the other positions [7-9]. Interspersed with the $S$ domains are regions with low (transition zones) or zero sulfation; however, the transition zones contain a considerable fraction of the 6-O-sulfates in HS [10]. The ligand binding activities of HSPG/heparin depend on patterns of sulfation along the chains [2].

HS chains are dynamically regulated in development and during tumor progression $[11,12]$. Since these changes are central to the ligand binding properties of HSPGs, there is considerable interest in mechanisms that generate diversity of the chains. One such mechanism is through regulated expression of enzymes involved in the biosynthesis of heparan sulfate, for example, the sulfotransferases that modify HS chains [13]. Another potential mechanism is through the action of extracellular endosulfatases that remove specific sulfation modifications from intact GAG chains. The first enzyme identified in this category was QSulf-1, which was discovered in quail embryo [14]. Stimulated by this work, we cloned cDNAs encoding Sulf1 and a new member of the family, Sulf-2, in mouse and human [15]. We showed that both Sulf- 1 and Sulf- 2 are secreted into conditioned medium when they are expressed in Chinese hamster ovary (CHO) cells. Both possess endoglucosamine-6-sulfatase activity against intact heparin with an optimum at neutral $\mathrm{pH}$. The enzymes liberate sulfate groups from the C-6 position of glucosamine residues on trisulfated $-\mathrm{IdoA}\left(2-\mathrm{OSO}_{3}\right)$ $\mathrm{GlcNSO}_{3}\left(6-\mathrm{OSO}_{3}\right)$ - disaccharide units of heparin. A similar activity for QSulf-1 has now been confirmed on HS chains $[16,17]$. This trisulfated disaccharide structure occurs within the S-domains and is known to be a key element in many of the protein ligand interactions of heparin and HS (see below).

The transcripts corresponding to QSulf- 1 and its rat orthologue (RFP-Sulf-1) demonstrate complex spatiotemporal regulation during embryonic development $[14,18]$ and QSulf-1 plays an essential role in Wnt-dependent differen- tiation of somites into muscle in quail [14]. In addition, in vitro assays have demonstrated that QSulf-1 promotes both Wnt [14] and bone morphogenetic protein [17] signaling via its sulfatase activity. Less is known about the distribution and function of the Sulfs in adult tissues. However, some interesting correlations have been revealed in tumors. Lai and colleagues have reported downregulation of Sulf- 1 transcripts in human ovarian cancer and a subset of hepatocellular carcinomas [19-21]. These workers and others have stressed the potential role of the enzyme in down-modulating certain signaling pathways involved in cell proliferation, since over-expression of Sulf- 1 reduces signaling by FGF-2, HB-EGF, or HGF [19-22]. In striking contrast to the results in ovarian cancer, increased levels of SULF1 or SULF2 transcripts are observed in other human cancers including breast and pancreatic carcinomas [23-25]. Upregulation of Sulf-2 at both the transcript and protein levels has been established in two mouse models of mammary carcinoma [25]. Furthermore, cultured human breast carcinoma cells release enzymatically active Sulf- 2 into conditioned medium. The upregulation of Sulf- 2 raises the possibility that it may be involved in promoting tumor progression [24,25]. Indeed, we have shown that Sulf-2 has pro-angiogenic activity, a relevant function for contributing to tumorigenesis [25].

Even before the discovery of the Sulfs, the glucosamine-6sulfate modification of HS was the focus of considerable interest. Thus, it has been shown that suppressing the expression of heparan sulfate 6-O-sulfotransferases via gene silencing strategies has pronounced developmental consequences in both Drosophila and Zebrafish development $[26,27]$. Secondly, binding studies with heparin/HS fragments and chemically modified heparins point to an essential contribution of the glucosamine-6-sulfate modification to their interaction with various protein ligands, including FGF-1 [28], FGF-10 [29], PDGF [30], VEFG [31], hepatocyte growth factor [32], lipoprotein lipase [33], herpes simplex glycoprotein C [34], noggin [17], and L- and P-selectin [35]. Here, we have taken advantage of recombinant Sulf-2 generated in 293 cells and of native Sulf- 2 obtained from conditioned medium of a breast carcinoma cell line to explore the range of activities for this enzyme. We have established an ELISA to examine the effects of Sulf- 2 from these two sources on the interaction of several growth factors and chemokines with immobilized heparin/HS. We found that pre-treatment of heparin with Sulf-2 significantly reduced its reactivity with certain ligands but not others ("pre-binding effect") and the enzyme also dissociated heparin-ligand complexes ("post-binding effect") raising the possibility that it may be involved in mobilizing HS-bound ligands in the ECM and basement membranes. 

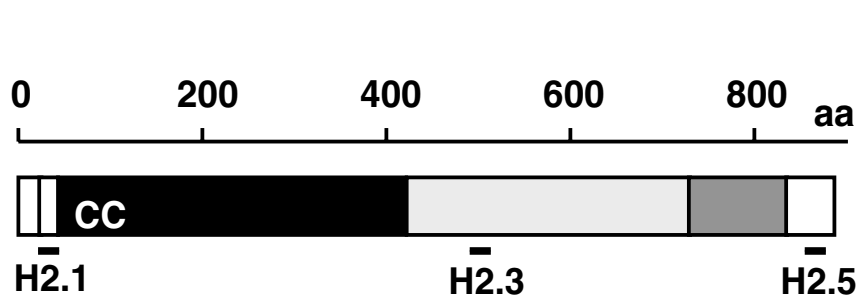

H2.1

\section{Sulfatase Region \\ G6S-related Region}

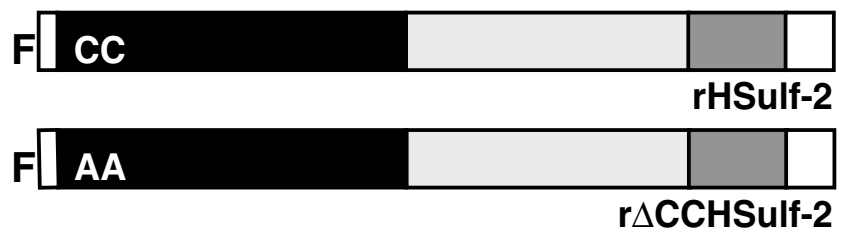

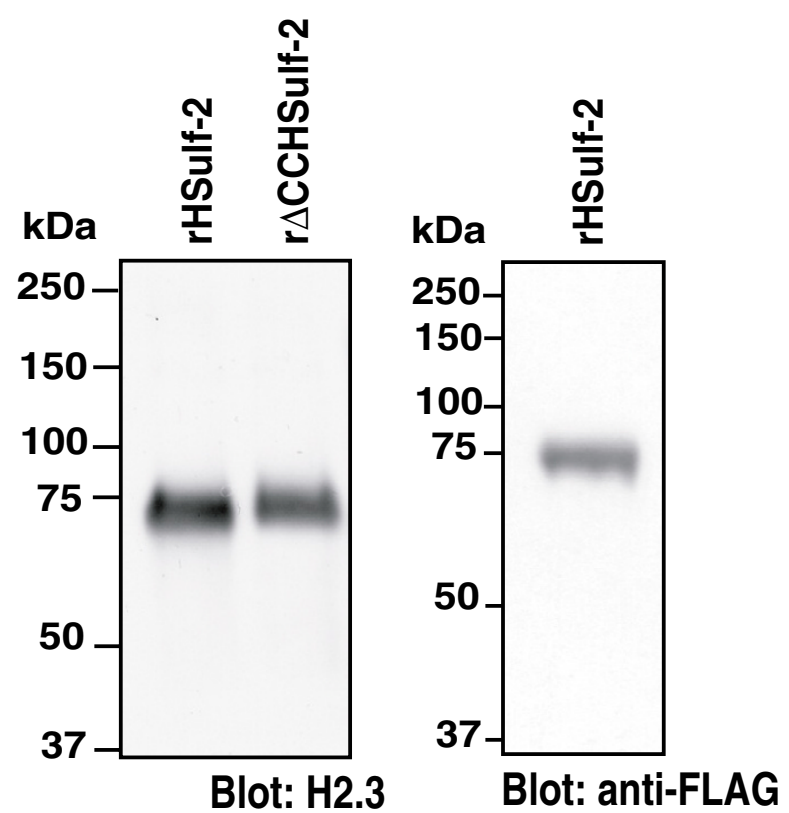

C
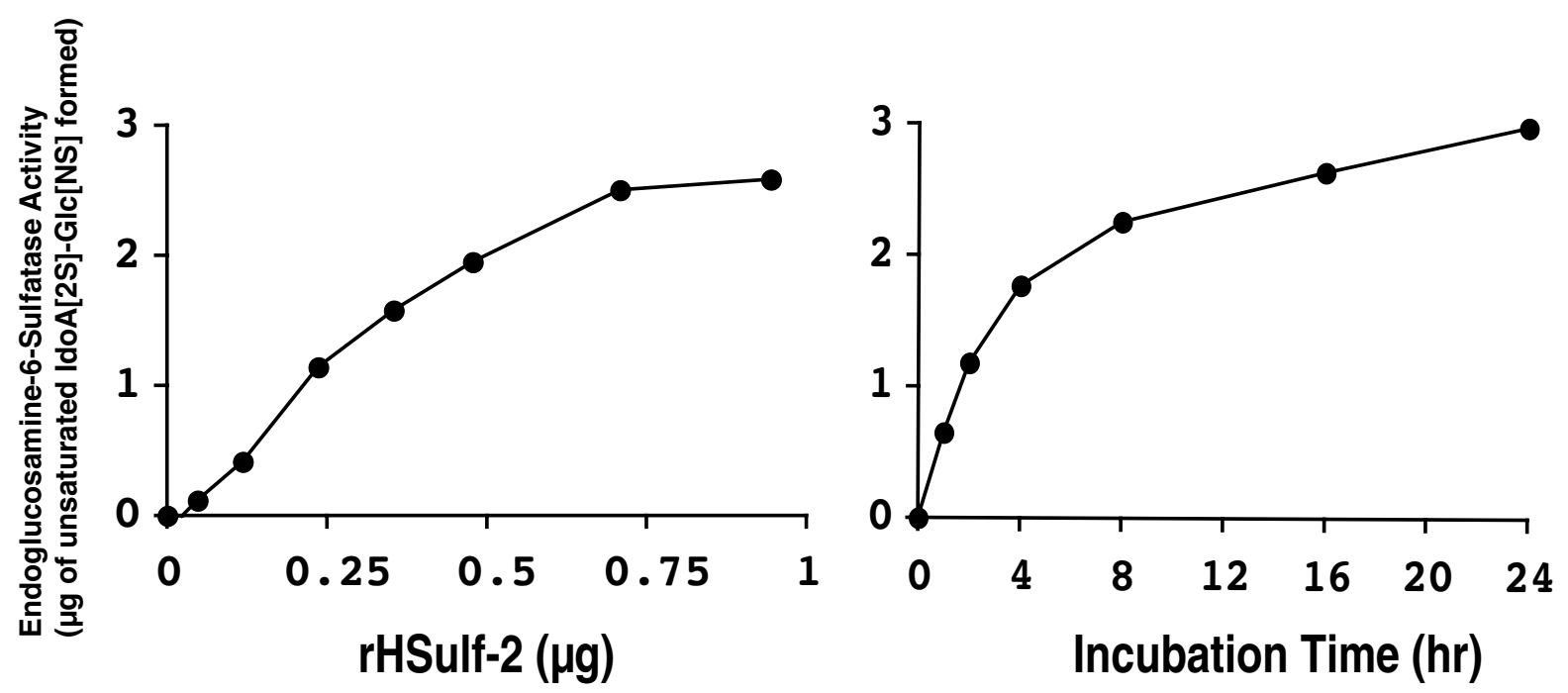

Figure I

Expression and characterization of a recombinant HSulf-2. (A) Domains in HSulf-2 are schematically presented. Positions of peptides that are used to develop polyclonal antibodies are shown. A recombinant protein with a N-terminal FLAG-tag (F) ( $r$ Sulf-2) and an enzymatically inactivated protein ( $r \Delta C C H S u l f-2)$ were designed and produced as described [25]. (B) Purified rHSulf-2 and $\mathrm{r} \Delta \mathrm{CCHSulf-2}$ produced in 293 cells were blotted with $\mathrm{H} 2.3$ anti-HSulf-2 antibody. A $72-\mathrm{kDa}$ and a $74 \mathrm{kDa}$ band were detected, respectively. rHSulf-2 was also blotted with a FLAG antibody. (C) Endoglucosamine-6-sulfatase activity of rHSulf-2 was measured as a function of enzyme concentration (left panel, $4 \mathrm{~h}$ incubation time) and reaction time (right panel, $240 \mathrm{ng}$ of rHSulf-2) as described in Methods. rHSulf-2 liberated sulfate groups on C-6 position of glucosamine residues within trisulfated disaccharide units in heparin. 
A

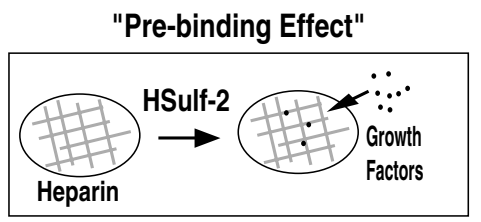

B
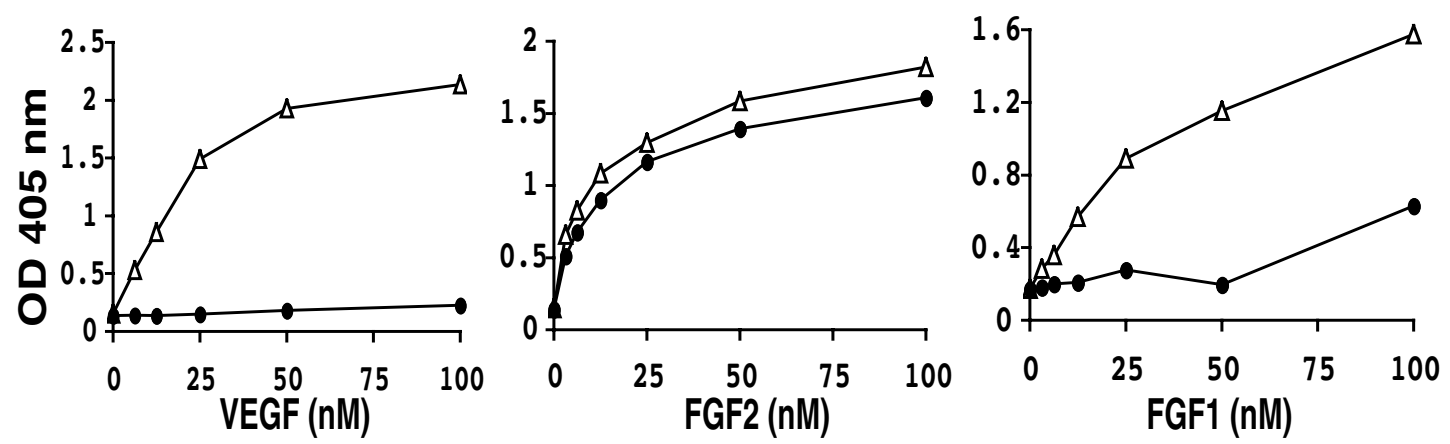

C
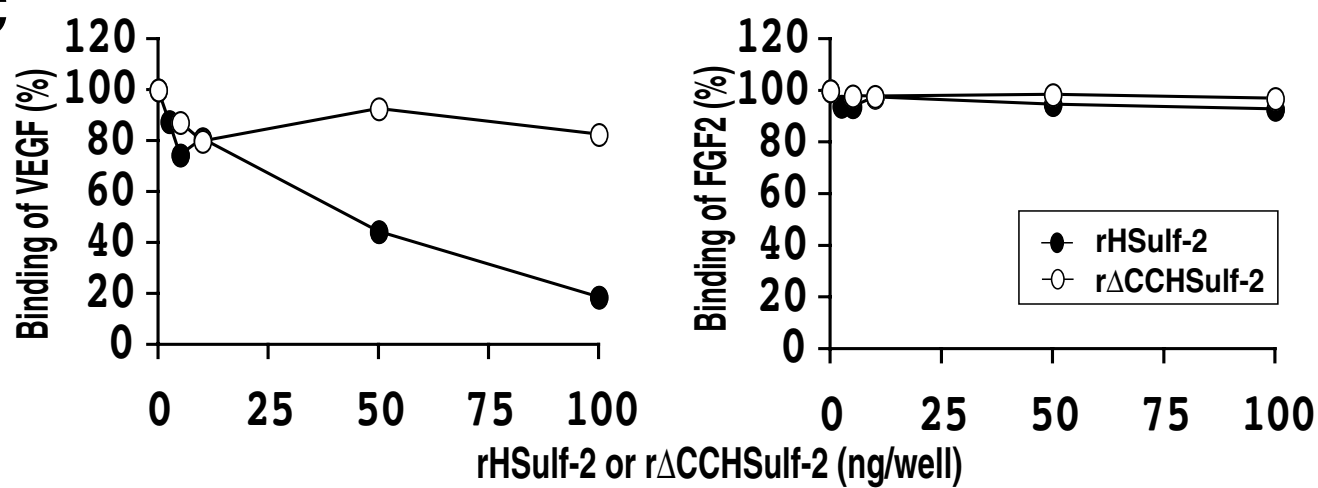

D
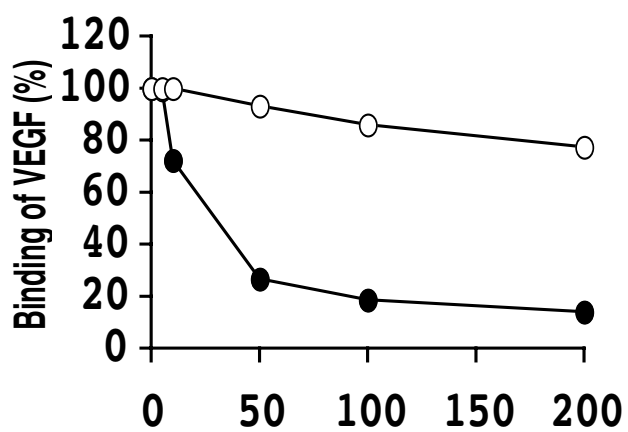

rHSulf-2 or r $\Delta$ CCHSulf-2 (ng/well)

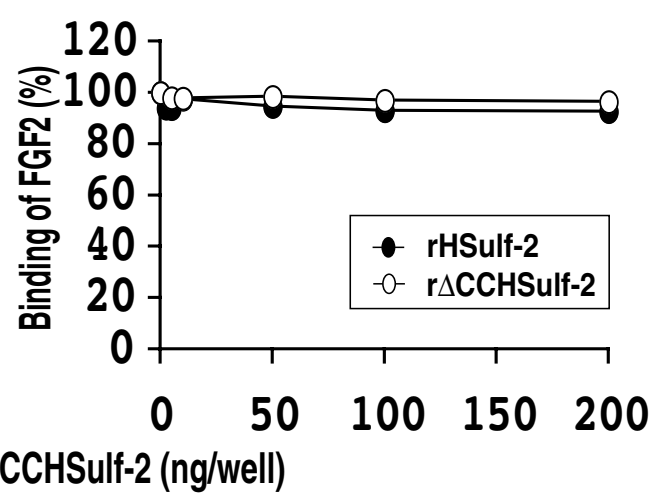

Figure 2

Sulf-2 effects on pre- and post-binding assays for VEFG and FGF-2. (A) Solid phase binding assays to measure "prebinding effect" and "post-binding effect" are schematically shown. HSulf-2 was incubated with immobilized heparin before or after adding heparin-binding factors. Specific primary antibodies quantified the amount of factor bound to immobilized heparin. (B) Binding of ligand $\left(\mathrm{VEGF}_{165}\right.$, FGF-2 or FGF-I) to immobilized heparin-BSA as a function of ligand concentration with or without Sulf-2 treatment of heparin-BSA. $\triangle$ denotes binding of protein to untreated heparin-BSA and 0 denotes binding of VEGF, FGF-2 or FGF-I to rHSulf-2 treated heparin-BSA in pre-binding assay. (C) "Pre-binding effect" of rHSulf-2 (O) or r $\Delta$ CCHSulf-2 $(O)$ on ligand binding (VEFG or FGF-2) to heparin-BSA as a function of enzyme concentration. (D) "Post-binding effect" of rHSulf-2 (O) or $\mathrm{r} \triangle \mathrm{CCHSulf-2}(\mathrm{O})$ on ligand binding (VEFG or FGF-2) to heparin-BSA as a function of enzyme concentration. All the results shown are representative of two independent experiments. 
Table I: Estimated dissociation constants for the interaction of ligands with immobilized heparin-BSA and heparan sulfate (HS)BSA

\begin{tabular}{ccc}
\hline Ligand & \multicolumn{2}{c}{$\mathrm{K}_{\mathrm{d}}$ value $(\mathrm{nM})$} \\
& Heparin-BSA & HS-BSA \\
\hline VEGF & 12.5 & $>200$ \\
FGF-I & 9.2 & 26 \\
FGF-2 & 8.6 & N.D. \\
CXCLI2 (SDF-I) & 75 & N.D. \\
CCL2I (SLC) & 5.5 & N.D. \\
CXCL8 (IL8) & $>180$ & N.D. \\
\hline
\end{tabular}

Each $\mathrm{K}_{\mathrm{d}}$ value was estimated from the concentration of ligand needed for half-maximal saturation. In the cases of IL-8 binding to heparinBSA and VEGF binding to HS-BSA, saturation was not observed at the highest concentration tested.

N.D., not determined.

\section{Results \\ Effect of recombinant HSulf-2 on the binding of VEGF ${ }_{165}$, FGF-I and FGF-2 to heparin}

We wanted to know if Sulf-2, as a 6-O endosulfatase, could modulate the interaction of known heparin-binding growth factors to heparin. We prepared and purified amino-terminal FLAG-tagged HSulf-2 (rHSulf-2) from stably transfected kidney 293 cells (Figs. 1A and 1B). The major rHSulf-2 component detected by the H2.3 antibody migrated with an apparent molecular weight of $72 \mathrm{kDa}$. Immunoblotting of rHSulf-2 with a FLAG antibody revealed a protein band of the same molecular weight (Fig. 1B). We conclude that the $72 \mathrm{kDa}$ component represents an $\mathrm{N}$-terminal subunit with a C-terminal truncation. It should be noted that there are several potential furin cleavage sites that are C-terminal to the position of the peptide immunogen (aa 484-504) [15]. It is not known at present whether protein processing is necessary for enzymatic activity against heparan sulfate substrates. We also prepared an enzymatically-inactive mutant of HSulf2 [15] in which two essential cysteines were mutated to

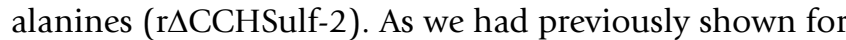
CHO cell-produced material [15], rHSulf-2 exhibited endosulfatase activity against heparin in a concentrationand time- dependent manner (Figs. 1C and 1D). The assay employs HPLC to examine to the disaccharide composition of treated and untreated heparin (see Methods). After $24 \mathrm{~h}$ of enzyme treatment, $80 \%$ of the trisulfated disaccharides were converted to the disaccharide products. The mutant protein was inactive in this assay (data not shown). We next developed solid phase ELISAs to measure the binding of protein ligands to immobilized heparin-BSA. Antibodies directed to the ligands were used for detection. For "pre-binding" effects, we first treated heparin-BSA with rHSulf-2 and then tested for its ability to support ligand binding (Fig. 2A). For "post-binding" effects, we determined the ability of rHSulf- 2 to release the ligand from a preformed complex with heparin-BSA (Fig. 2A).

We initially focused our attention on three growth factors: VEGF $_{165}$, FGF-1 and FGF-2. Sulfate groups in heparin/HS, including glucosamine-6-sulfates, are required for the interaction of VEGF $_{165}$ and FGF-1 with heparin/HS $[28,31,36]$. In contrast, FGF-2 binding to heparin/HS depends on N-sulfation and iduronate-2-sulfation but not on 6-O-sulfation $[28,36,37]$. We observed saturable binding of VEGF ${ }_{165}$, FGF-1 and FGF-2 to heparin-BSA (Figs. 2B and $4 \mathrm{~B}$ ). We estimated $\mathrm{K}_{\mathrm{d}}$ 's for these interactions and the binding of three chemokines (CXCL12, CCL21, and CXCL8) to heparin-BSA (Table 1). Negligible binding was seen when the wells were coated with BSA alone (data not shown). As a positive control to eliminate heparindependent binding, we pre-digested heparin-BSA with a mixture of heparinases (0.2 mU of heparinase I, $0.1 \mathrm{mU}$ of heparinase II and $0.04 \mathrm{mU}$ of heparinase III) for $4 \mathrm{~h}$ and found that this digestion reduced the binding of VEGF by $>92 \%$. Treatment of heparin with rHSulf-2 reduced the binding of varying concentrations of VEGF to heparin-BSA almost to background levels (Fig. 2B). rHSulf-2 treatment diminished the binding of FGF-1 by $>60 \%$. In contrast, rHSulf- 2 had only a negligible effect on the binding of FGF-2 to heparin (Fig. 2B). To determine the efficacy of the enzyme, we fixed the concentration of ligand at approximately its $\mathrm{K}_{\mathrm{d}}$ and tested varying concentrations of rHSulf-2 or the inactive mutant, $\mathrm{r} \Delta \mathrm{CCHSulf-2}$. For FGF-2, only minimal effects of rHSulf-2 were seen up to $100 \mathrm{ng}$ of the enzyme, whether tested in the pre-binding (Fig. 2C) or post-binding assay (Fig. 2D). In contrast, treatment of heparin-BSA with 50 ng or more of rHSulf-2 substantially reduced its binding to VEGF in a dosedependent manner (Fig. 2C), whereas the mutant enzyme was largely inactive. In the post-binding assay, rHSulf-2 was also efficacious in releasing VEGF from preformed complexes with heparin-BSA (Fig. 2D, Table 2). The slight inhibitory effects of $\mathrm{r} \triangle \mathrm{CCHSulf}-2$ (Figs. 2C and 2D) in both the pre-binding and post-binding assays may be attributable to a competing heparin-binding activity of Sulf-2 protein due to its highly basic hydrophilic domain [15].

\section{Effects of HSulf-2 on chemokine binding to heparin-BSA}

Chemokines are also heparin/HS-binding proteins [6]. However, limited information is available about the specific sulfation requirements for these interactions. We therefore took advantage of rHSulf- 2 to determine the contributions of glucosamine-6-sulfation to these interactions. rHSulf- 2 was very effective in reducing the interaction of SDF-1 (CXCL12) with heparin-BSA in both prebinding and post-binding assays (Fig. 3A and 3B, Table 2). In contrast, rHSulf-2 had only partial inhibitory effects on the binding of SLC (CCL21) to heparin-BSA (Fig. 3A). IL- 
Table 2: Comparison of rHSulf-2 requirements for mobilization of heparin-bound ligands

\begin{tabular}{cc}
\hline Ligand & $\begin{array}{c}\text { Concentration required for 50\% } \\
\text { release of heparin-bound ligand }\end{array}$ \\
& rHSulf-2 $(\mu \mathrm{g} / \mathrm{mL})$ \\
\hline VEGF & 0.34 \\
FGF-I & 0.36 \\
FGF-2 & $>4.0$ \\
CXCL12 (SDF-I) & 0.44 \\
CCL21 (SLC) & 3.1 \\
CXCL8 (IL-8) & 3.4 \\
CXCLI0 (IP- I0) & 2.0 \\
\hline
\end{tabular}

a $K_{d}$ for heparin-BSA was $62 \mathrm{nM}$. The fixed concentration of ligand tested in the assay was $50 \mathrm{nM}$.

8 (CXCL8) bound less well to heparin-BSA, but rHSulf-2 treatment still attenuated the interaction (Fig. 3A).

\section{Analysis of the activity of native HSulf-2 in MCF-7 conditioned medium}

SULF2 transcripts are upregulated in breast, central nervous system and colon carcinomas [24,25]. Moreover, transcripts are detected in some cultured human breast carcinoma cell lines and the mRNA-positive cells release Sulf-2 protein in their conditioned medium [25]. Sulf-2 expression is highest in the conditioned of MCF-7 cells and we have demonstrated that the secreted protein has associated arylsulfatase activity using 4-methylumbelliferyl sulfate as the substrate [25]. As shown in Fig. 4A, the $\mathrm{CM}$ from these cells exhibited concentration- and timedependent endoglucosamine-6-sulfatase activity against heparin. In pilot experiments, the $\mathrm{CM}$ also showed activity against bovine intestinal heparan sulfate (HS) producing a substantial reduction in the amount of the trisulfated disaccharide with a corresponding increase in the amount of the disulfated disaccharide product (data not shown). Using $\mathrm{CM}$ as a source of the native enzyme, we analyzed the "pre-binding" and "post-binding" effects on the binding of VEGF or FGF-2 to heparin. Consistent with the rHSulf-2 findings, pretreatment of heparin-BSA with a fixed concentration of MCF-7 CM strongly reduced the subsequent binding of VEGF ${ }_{165}$ or FGF-1 but had no effect on the binding of FGF-2 (Fig. 4B). In a dose-dependent manner, CM prevented (Fig. 4C) and reversed (Fig. $4 \mathrm{D})$ the interaction of VEGF $_{165}$ or FGF-1 with heparinBSA. Similar effects were observed with SDF-1 (data not shown). In contrast, the same range of CM concentrations had no appreciable effect on the binding of FGF-2 to heparin-BSA in either the pre-binding or post-binding assays (Figs. 4C and 4D). To confirm that the reductions in heparin binding were, in fact, due to Sulf-2, we employed anti-HSulf-2 antibodies [25] for immunodepletion of Sulf-2 from MCF CM. Pre-clearing was carried out by incubating $\mathrm{CM}$ with protein A-Sepharose complexed to a mixture of two specific antibodies and then centrifuging the mixture. As shown by Western blotting, the specific antibodies removed the majority of HSulf- 2 protein from the $\mathrm{CM}$, whereas control IgG removed only a relatively small amount of the protein (Fig. 4E). In parallel with the depletion of HSulf-2 protein, the "pre-binding" activity of the precleared $\mathrm{CM}$, measured with respect to $\mathrm{VEGF}_{165}$ binding, was greatly diminished as compared to that of the control IgG-treated CM (Fig. 4F).

\section{Effects of HSulf-2 on heparan sulfate interactions}

Heparin is a structural analogue of the S-domains of heparan sulfate. We wanted to determine whether the effects of Sulf-2 on heparin interactions would be repeated with bona fide heparan sulfate. For this purpose, we conjugated BSA with heparan sulfate chains (HS-BSA) that were isolated from porcine intestinal mucosa. FGF-1 bound to HS-BSA, although with a 3-fold lower affinity than to heparin-BSA (Fig. 5, Table 1). This binding was abolished by pre-digestion of the HS chains with heparinases. Pretreatment of the HS-BSA with MCF-7 CM or rHSulf-2 substantially diminished FGF-1 binding (55$70 \%$ reduction), whereas $\mathrm{r} \Delta \mathrm{CCHSulf-2}$ did not exert this effect (Fig. 5).

\section{Discussion}

The Sulfs are 6-O endosulfatases that act on the trisulfated disaccharide unit (- $\mathrm{IdoA}\left(2-\mathrm{OSO}_{3}\right)-\mathrm{GlcNSO}_{3}\left(6-\mathrm{OSO}_{3}\right)$-) which is the most common unit in heparin but is largely confined to the S-domains of HS [15-17]. As the heterogeneous pattern of sulfation within $S$ domains is known to dictate the binding specificity of many proteins for heparin/HS [7], the Sulfs could potentially regulate those interactions with a dependence on the presence of trisulfated disaccharides within the binding motif. Here, we have employed Sulf-2 as a tool to explore the binding requirements of several proteins, some of which had been previously characterized and others whose binding requirements were largely unknown. Previous work has shown that QSulf-1 treatment of soluble recombinant form of an HSPG (Glypican-1) reduced its ability to bind a Wnt ligand [16]. Also, the interaction of Noggin with cell surface HSPGs was diminished by the overexpression of QSulf-1 in the cells [17]. In the present study we have taken advantage of two sources of soluble HSulf-2: recombinant enzyme purified from stably transfected 293 cells and a natural form of the enzyme in $\mathrm{CM}$ of a human breast carcinoma cell line (MCF-7). It should be noted that we have not been able to obtain expression of high level of Sulf-1 in CM of transfected 293 cells, nor have we yet identified a soluble form of this enzyme from a native source. 
A
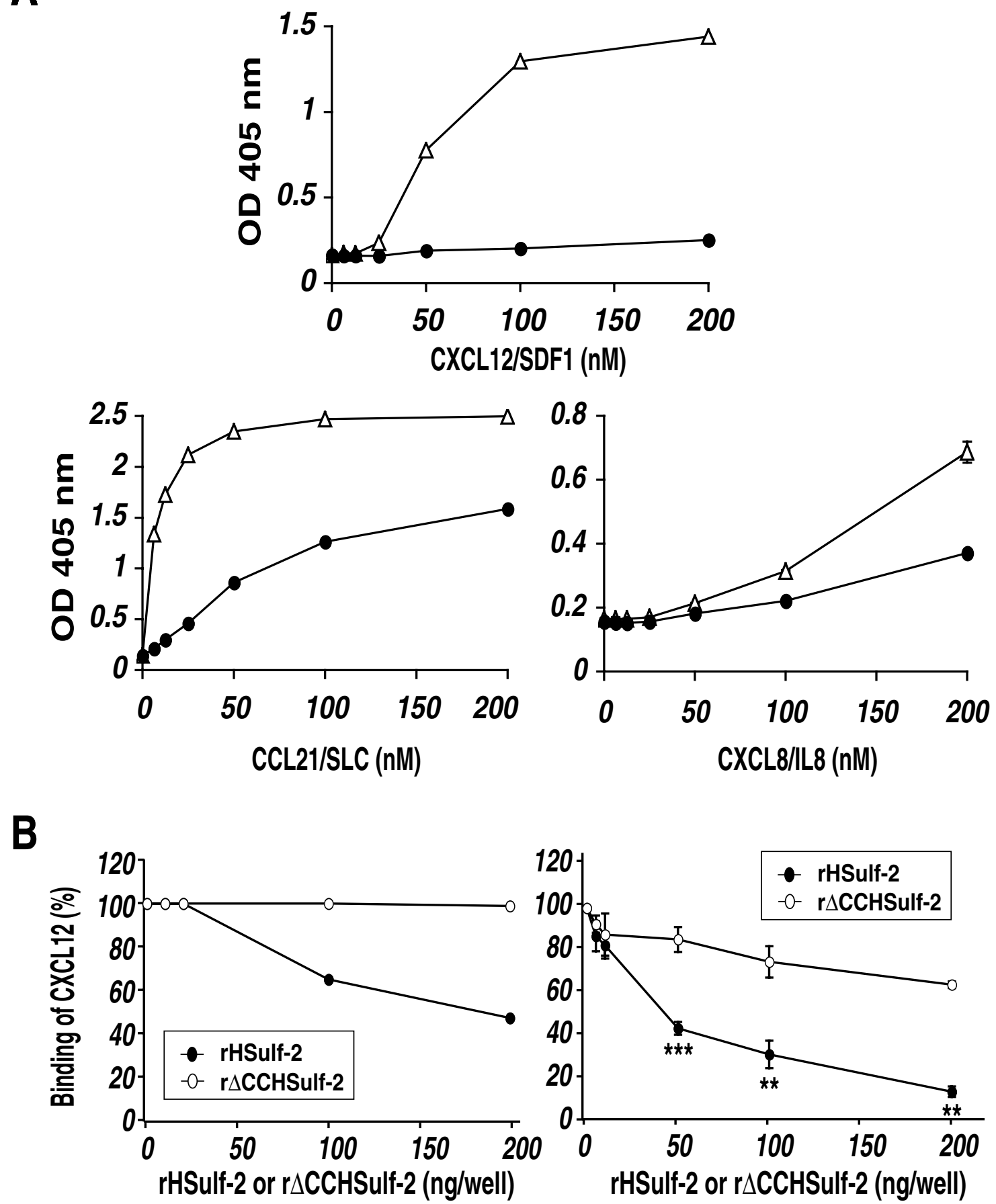

Figure 3

Sulf-2 effects on pre- and post-binding assays for chemokines. (A) Binding of CXCLI2 (SDF-I), CCL2I (SLC) and CXCL8 (IL8) to immobilized heparin-BSA as a function of ligand concentration with or without Sulf-2 treatment of heparinBSA. $\Delta$ denotes binding of chemokines to untreated heparin-BSA and - denotes binding of chemokines to rHSulf-2 treated heparin-BSA in pre-binding assay. (B) "Pre-binding effect" (left panel) and "post-binding" effect (right panel) of rHSulf-2 (O) or $\mathrm{r} \triangle \mathrm{CCHSulf-2}(\mathrm{O})$ on ligand binding $(C X C L I 2)$ to heparin-BSA as a function of enzyme concentration. Values represent the means \pm S.D. of triplicate determinations in the binding assays for CXCL8 and CXCLI2. Statistical analysis was carried out using Student's $t$ test. **, $\mathrm{p}<0.0 \mathrm{I} ;{ }^{* * *}, \mathrm{p}<0.00 \mathrm{I}$. The other data are representative of two independent trials. 

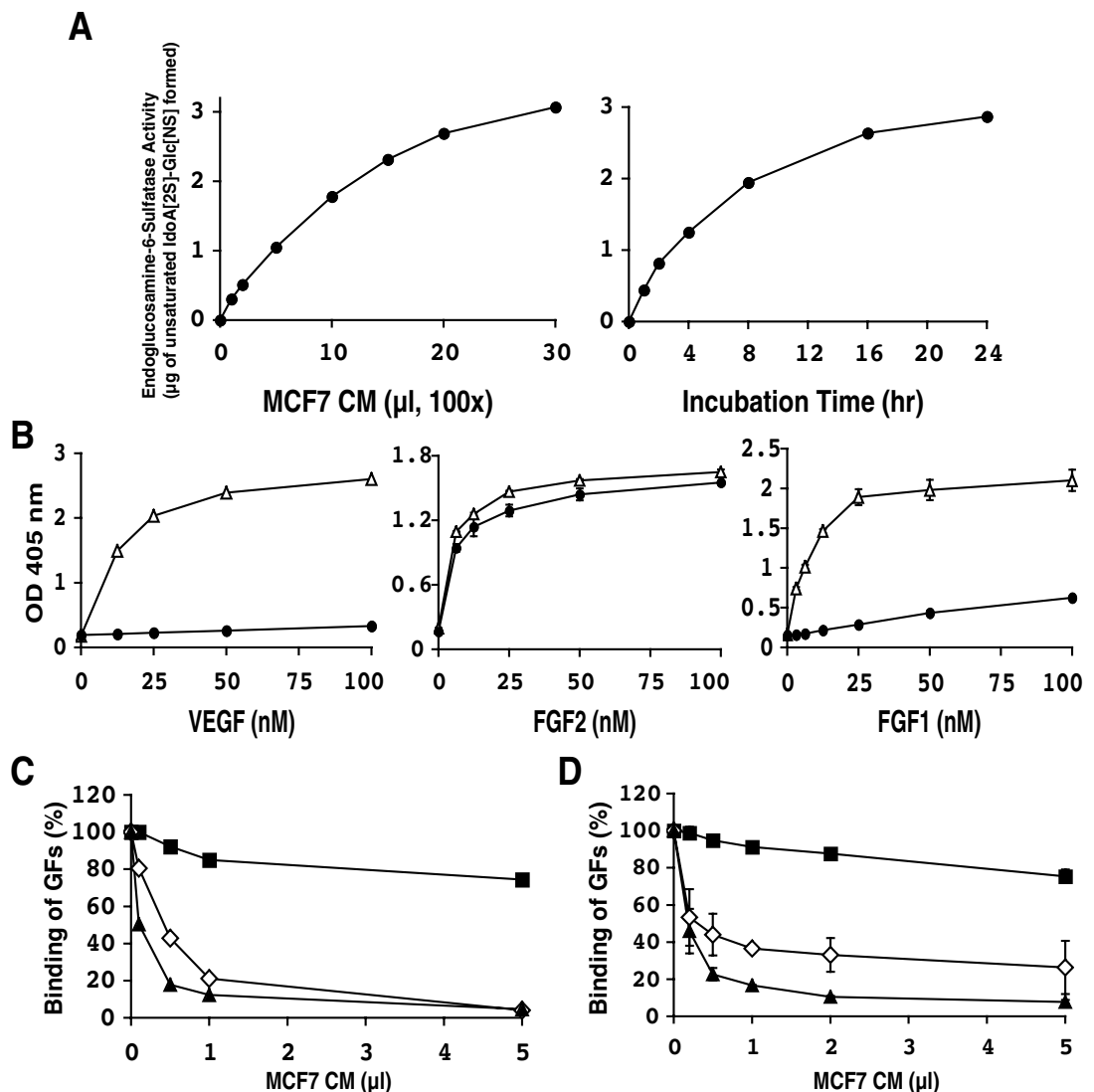

D
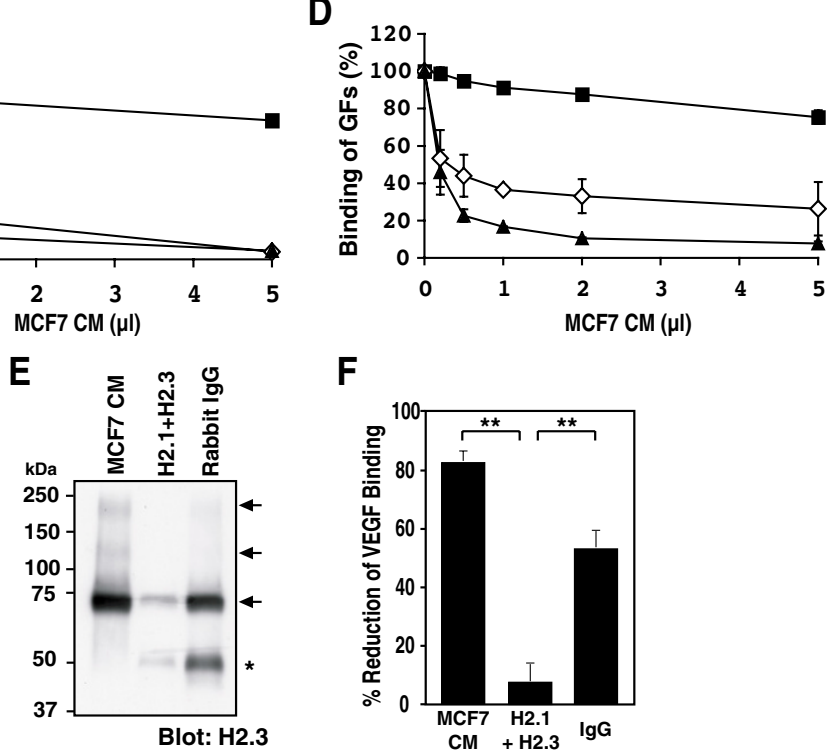

$\mathbf{F}$

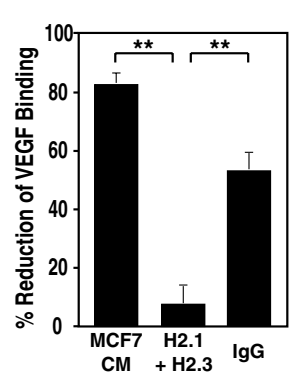

\section{Figure 4}

Sulf-2 activity in MCF-7 CM. (A) Endosulfatase activity of CM on heparin as a function of CM volume (left panel, $4 \mathrm{~h}$ incubation time) and reaction time (right panel, $10 \mu \mathrm{l}$ of CM). (B) Binding of ligand (VEGF 165 , FGF-2 or FGF-I) to immobilized heparin-BSA as a function of ligand concentration with or without CM treatment of heparin-BSA. $\triangle$ denotes binding of ligand to untreated heparin-BSA and denotes binding of ligand to CM treated heparin-BSA in pre-binding assay. Means of triplicate determinations \pm S.D. are shown. In those cases where the error bars are not apparent, the S.D. values are smaller than the symbols. (C) "Pre-binding effect" of CM on ligand binding (VEGF ${ }_{165}$, black triangles; FGF-2, black squares; FGF-I, open diamonds) as a function of CM volume. These results are representative of two independent experiments (D). "Post-binding effect" of CM on ligand binding (VEGF 165 , black triangles; FGF-2, black squares; FGF-I, open diamonds) as a function of CM volume. Means of triplicate determinations are shown. S.D. values for FGF-I are indicated. The S.D. values for VEGF and FGF-2 are smaller than the symbols. (E) Immuno-depletion of HSulf-2 protein by specific antibodies. MCF-7 CM was precleared with Sulf-2 antibodies $(\mathrm{H} 2 . \mathrm{I}$ and $\mathrm{H} 2.3)$ or control lgG conjugated to beads and then blotted for Sulf-2 protein $(\mathrm{H} 2.3)$. Arrows denote specific bands detected in the untreated MCF-7 CM ( 240, 135 and $72 \mathrm{kDa})$. The $\sim 50 \mathrm{kDa}$ bands indicated by the asterisk are derived from the IgG used for the precipitation (F). Immuno-depletion of HSulf-2 activity by specific antibodies. The precleared CMs in $\mathbf{E}$ were tested in a pre-binding assay for effects on VEGF binding to heparin-BSA. The partial depletion of activity by control IgG reflects the tendency of Sulf-2 to bind nonspecifically to Sepharose beads (not shown). Means and S.D. values are shown for triplicate determinations. Statistical analysis was carried out using Student's $t$ test. **, $p<0.01$. 


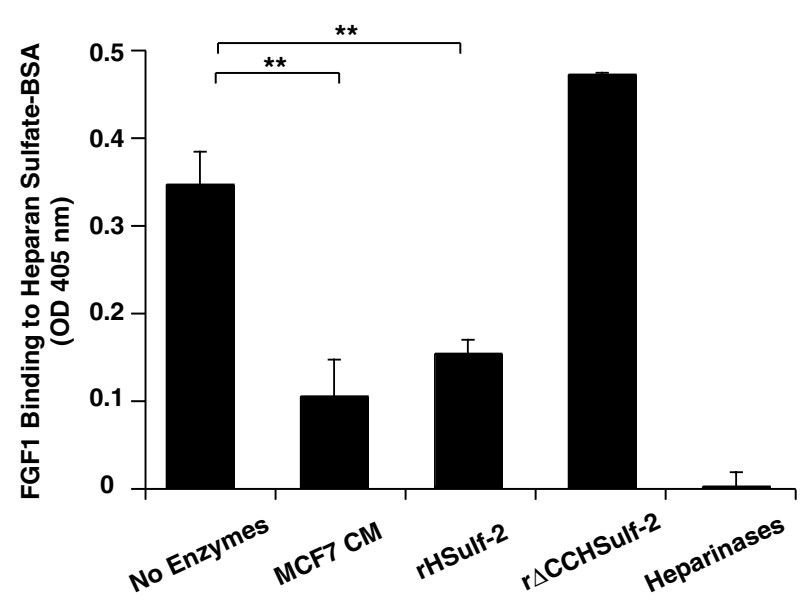

Figure 5

The effect of Sulf-2 on FGF-I binding to heparan sulfate-BSA. FGF-I binding to heparan sulfate-BSA was measured after the following treatments of the conjugate: no treatment; MCF-7 CM; rHSulf-2; $r \Delta C C H S u l f-2 ;$ or a mixture of heparinases. Values represent the means \pm S.D. of three separate determinations. Statistical analysis was carried out using Student's $t$ test. ${ }^{* *}, \mathrm{p}<0.01$.

We have previously shown that native Sulf-2 in MCF-7 $\mathrm{CM}$ has arylsulfatase activity [25]. In the present study, we have used HPLC to demonstrate that MCF-7 CM possesses endosulfatase activity against intact heparin. This result has also been established by an alternative approach using mass spectroscopy [38]. Employing an ELISA based on binding of protein ligands to heparin-BSA conjugate, we found that rHSulf-2 strongly modulated the binding of VEGF $_{165}$, FGF-1, and SDF-1 to porcine intestinal heparin. In the case of FGF-1, the inhibitory effect of Sulf- 2 was also demonstrated for heparan sulfate chains as well, using a HS-BSA conjugate. All of the effects obtained with the recombinant enzyme were observed for MCF-7 CM, and we confirmed that the activity in the CM was due to Sulf-2. The porcine intestinal heparin used in this study contained $70 \%$ trisulfated disaccharides, $18 \%$ disulfated disaccharides, 7\% monosulfated disaccharides and 5\% unsulfated disaccharides (data not shown). Based on our previous work [15] and the present study, we estimate that about $80 \%$ of the total trisulfated disaccharides in heparin-BSA was converted into disulfated disaccharides by Sulf-2. Thus, only about $22 \%$ of the overall sulfate moieties were removed by the enzyme treatment, arguing against the possibility that the reduced binding of selective protein ligands to treated heparin was due to a reduction in overall charge. As heparan sulfates have limited Sdomains [7], Sulf-2 would be predicted to have an even smaller effect on the global sulfation of HSPGs. A further indication of the selectivity of Sulf- 2 is that there is no relationship between the estimated $\mathrm{K}_{\mathrm{d}}$ for binding of each ligand to heparin-BSA (Table 1) and the susceptibility of the interaction to the enzyme (Table 2).

The Sulf-2 effects on FGF-1 binding were anticipated based on a number of correlative studies [28,39], which have implicated the trisulfated disaccharide motif as a binding element in HS chains. Our $\mathrm{VEGF}_{165}$ results are compatible with a previous study in which chemical 6-Odesulfation of heparin strongly weakened its ability to interact with $\mathrm{VEGF}_{165}$ [31]. However, our findings provide the first direct evidence that 6-O-sulfation of heparin within the context of the trisulfated disaccharide motif is essential for the interaction. The majority of VEGF isoforms are able to bind to heparin/HS [40], and it is anticipated that our results will generalize to these other forms as well. With respect to SDF-1, it has long been known that this highly basic chemokine binds relatively strongly to heparin [41], but the fine specificity of the interaction has not previously been explored. SLC and IL-8 showed a partial sensitivity to the desulfation effects of Sulf- 2 on heparin. This partial susceptibility implies that the 6-Osulfation of the trisulfated disaccharide can contribute but is not absolutely required for a measurable binding interaction with heparin. One important avenue for future investigation is based on our observation that Sulf-2 strongly modulated the interactions of two chemokines (SDF-1 and SLC) with heparin. SDF-1 has been implicated in a diverse range of processes such as lymphocyte chemotaxis, stem cell homing and retention, tissue repair, angiogenesis, and organ-specific metastasis [42], whereas SLC is important in lymphoid organ homeostasis and inflammation [43]. Thus, Sulf-2 though effects on the ECM-association of chemokines could have important roles in a number of normal and pathophysiologic processes. HSulf-1 with an apparently indistinguishable enzymatic activity [15] may exert similar effects on HSPG-bound growth factors and chemokines.

It is well established that one function of heparan sulfate proteoglycans in the ECM and basement membranes is to sequester protein ligands away from signal transduction receptors [44,45]. A known mechanism to regulate the mobilization of such factors is through the action of heparanase, an endo-ß-D-glucuronidase that degrades heparan sulfate chains into relatively large fragments [46]. This enzyme is present in a number of normal cell types (e.g., leukocytes, platelets, cytotrophoblasts) and is upregulated in several cancers. Expression of heparanase in a number of settings elicits angiogenesis, apparently through the release of HSPG-bound angiogenic factors $[44,47]$. Our finding that Sulf-2 can reverse the association between heparin and angiogenic factors (e.g., VEGF) suggests the possibility of functional parallels between these two enzymes. Sulf-2 may mobilize VEGF or other 
angiogenic factors sequestered in the ECM and increase their bioavailability to endothelial cells that express the appropriate signaling receptors. The ability of rHSulf- 2 to promote angiogenesis in the chick chorioallantoic membrane (CAM) assay is consistent with such a scenario [25]. Thus, the observed upregulation of Sulf- 2 in mammary carcinomas and its secretion from these cells could directly contribute to tumor angiogenesis and thus tumor growth. Sulf-2 derived from a cancer cell could also conceivably mobilize HSPG-bound growth factors that then act back on the cancer cell and thus trigger its own proliferation. The ability of QSulf-1 to promote Wnt signaling within the cells that express the enzyme provides a plausible paradigm for this type of autocrine pathway $[14,16]$. It should be borne in mind that in the context of some other signaling pathways (e.g., FGF-2 and HGF), Sulf-2 is likely to exert a negative effect.

\section{Conclusion}

As demonstrated in the present study, Sulf- 2 can modulate the interaction of a number of important bioactive proteins with heparin/HS. A major finding of our study is that Sulf-2 completely disrupts the interaction of certain factors with heparin. As expected, the factors for which Sulf-2 strongly blocks binding to heparin in the pre-binding format are the most susceptible to reversal effects in the post-binding assays (VEGF, FGF-1, and SDF-1). These observations indicate that, irrespective of the engagement of a protein ligand, Sulf-2 has access to the 6-O-sulfate group of the trisulfated disaccharide units of intact heparin. Recombinant Sulf-2 provides a valuable tool for investigating the specific sulfation requirements for heparin/HS interactions of interest. Furthermore, future application of the assays described herein will certainly expand the range of interactions that can be modulated by Sulf-2 and should enhance our understanding of the potential functional roles served by this enzyme in situ.

\section{Methods \\ Materials}

The following materials were obtained commercially from the source indicated. Heparin conjugated with bovine serum albumin (Heparin-BSA), BSA, heparinases (I, II and III) were from Sigma (St Louis, Mo., USA); heparan sulphate (porcine intestinal mucosal) from Organon (Oss, The Netherlands); DEAE-Sephacel from Sigma (Poole, UK); Phenyl-Sepharose CL-4B from Amersham Biosciences (Little Chalfont, UK); Protein A Sepharose beads from RepliGen (Needham, MA); recombinant human VEGF $_{165}$, human CXCL12 (SDF-1), anti-human VEGF antibody (Ab), anti-human FGF-1 Ab, anti-human FGF-2 Ab, anti-human CXCL12 Ab, anti-CXCL8 Ab and anti-human CCL21 Ab from R\&D Systems. All are polyclonal antibodies produced in goats. Recombinant human FGF-1 (acidic FGF), human FGF-2 (basic FGF), human CCL21 (SLC) and CXCL8 (IL-8) were from Leinco Inc. A biotinylated swine anti-goat IgG $(\mathrm{H}+\mathrm{L})$ antibody and a streptavidin conjugated with alkaline phosphatase were from Caltag. FLAG-tagged versions of HSulf-2 and the inactive mutant designated $\Delta \mathrm{CCHSulf-2}$ were produced in 293 cells and purified as previously described [25]. Polyclonal rabbit anti-bodies against HSulf-2 (H2.1 and $\mathrm{H} 2.3$ ) were generated and prepared as previously described [25].

\section{Heparan sulfate-BSA conjugate}

Porcine intestinal mucosal heparan sulfate was coupled, via its reducing end, to BSA based on the procedure of Najjam et al. [48]. Briefly, 2 mg of sodium cyanoborohydride was added to a mixture of $50 \mathrm{mg}$ of HS and $2 \mathrm{mg}$ of BSA in $2 \mathrm{ml}$ of $0.2 \mathrm{M}$ potassium phosphate buffer $\mathrm{pH} 8$. The mixture was then incubated for 2 days at $37^{\circ} \mathrm{C}$. After dilution to $10 \mathrm{ml}$ with $0.15 \mathrm{M} \mathrm{NaCl}, 20 \mathrm{mM}$ phosphate, pH7.4, it was applied to a $5 \mathrm{ml}$ column of DEAE-Sephacel equilibrated in the same solution. After washing with 0.15 $\mathrm{M} \mathrm{NaCl}$ solution, followed by buffered $0.4 \mathrm{M} \mathrm{NaCl}$, to remove reagents and any non-conjugated BSA, the HScontaining material was then step-eluted with $0.5 \mathrm{ml}$ aliquots of buffered $1.5 \mathrm{M} \mathrm{NaCl}$. HS-containing fractions were identified by spotting aliquots onto Whatman filter paper and staining with Azure A. The pooled fractions were adjusted to $3 \mathrm{M}$ in $\left(\mathrm{NH}_{4}\right)_{2} \mathrm{SO}_{4}$, by addition of solid $\left(\mathrm{NH}_{4}\right)_{2} \mathrm{SO}_{4}$, and then applied to a $2 \mathrm{ml}$ column of PhenylSepharose CL-4B equilibrated in $3 \mathrm{M}\left(\mathrm{NH}_{4}\right)_{2} \mathrm{SO}_{4}$. After washing with $3 \mathrm{M}\left(\mathrm{NH}_{4}\right)_{2} \mathrm{SO}_{4}$ to elute free $\mathrm{HS}$, the bound HS-BSA conjugate was step-eluted with $0.5 \mathrm{ml}$ aliquots of $0.15 \mathrm{M} \mathrm{NaCl}, 20 \mathrm{mM}$ phosphate pH7.4. Fractions containing conjugated BSA were identified by their absorbance at $280 \mathrm{~nm}$. The final product ran as a diffuse band, stainable with both Coomassie Blue and Azure A, close to the top of a $10 \%$ polyacrylamide SDS-PAGE gel and with a higher apparent MW than free BSA. The BSA content of the conjugate was assessed by absorbance at $280 \mathrm{~nm}$. The HS content was determined by digestion with a mixture of heparinases I, II and III, and measurement of the resulting increase in absorbance at $232 \mathrm{~nm}$. It was estimated that the average level of conjugation was 1-2 HS chains/BSA molecule.

\section{Preparation of recombinant Sulf-2 and CM from MCF-7 cells}

FLAG-tagged versions of active Sulf-2 (rHSulf-2) and inactive enzyme ( $\mathrm{r} \Delta \mathrm{CCHSulf-2)}$ were produced in stably transfected kidney 293 cells as described previously [25]. The purities of rHSulf- 2 and $\mathrm{r} \Delta \mathrm{CCHSulf-2}$ were estimated to be $90 \%$ and $80 \%$, respectively based on Coomassie blue staining of SDS-PAGE gels. The amount of Sulf-2 protein was quantified by the BCA assay (Pierce). The amounts of rHSulf- 2 and $\mathrm{r} \Delta \mathrm{CCHSulf}-2$ were equalized by an ELISA employing an anti-FLAG M2 antibody (Sigma) 
as the capture reagent and a mix of $\mathrm{H} 2.1$ and $\mathrm{H} 2.3$ antibodies for detection. The human breast carcinoma cell line, MCF-7, was grown in RPMI-1640 containing 10\% fetal calf serum in a $150 \mathrm{~mm}$-flask. Cells (80\% confluent) were rinsed with PBS and OptiMEM (Invitrogen) and then incubated in $25 \mathrm{ml}$ of OptiMEM at $37^{\circ} \mathrm{C}$ in $5 \% \mathrm{CO}_{2}$ for $72 \mathrm{~h}$. The $\mathrm{CM}$ was collected and then 100-fold concentrated on a Centricon-30. Subsequently, the concentrated $\mathrm{CM}$ was dialyzed into $50 \mathrm{mM}$ HEPES, pH 8.0.

\section{ELISAs for "pre-binding" and "post-binding" effects of HSulf-2}

The experimental design for these ELISA is schematically shown in Fig 2A. To immobilize heparin, $100 \mathrm{ng} / \mathrm{ml}$ of heparin-BSA in phosphate-buffered saline (PBS) was added to the wells $(100 \mu \mathrm{l} /$ well) of a 96-well plate (Immulon $2 \mathrm{HB}$, Dynex Labs). The plate was placed at $4{ }^{\circ} \mathrm{C}$ overnight. The wells were washed 3 times with PBS containing $0.1 \%$ Tween-20 (PBS-T) and then blocked with 3\% BSA (Sigma) in PBS-T at $25^{\circ} \mathrm{C}$ for $2 \mathrm{~h}$. To determine the effects of Sulf-2 on the ligand-binding activities of heparin ("prebinding" effects), the wells were washed as above and then incubated with $100 \mu \mathrm{l}$ of a reaction mixture containing $5 \mu \mathrm{mol}$ of HEPES, $\mathrm{pH} 7.6,1 \mu \mathrm{mol}$ of $\mathrm{MgCl}_{2}$ and enzyme (rHSulf-2, r $\Delta$ CCHSulf- 2 or MCF-7 CM) at $37^{\circ} \mathrm{C}$ for $4 \mathrm{~h}$. In the cases where we carried out dose response studies with protein ligands, incubation with the enzyme was overnight. The wells were washed 3 times with PBS-T and then incubated with $25 \mu \mathrm{l}$ of heparin-binding factors (25 nM VEGF, 12.5 nM FGF-2, 12.5 nM FGF-1, and 100 $\mathrm{nM}$ CXCL12) in PBS at $25^{\circ} \mathrm{C}$ for $30 \mathrm{~min}$. The wells were washed 3 times and incubated with $1 \mu \mathrm{g} / \mathrm{ml}$ of each primary antibody in $0.1 \% \mathrm{BSA} / \mathrm{PBS}(100 \mu \mathrm{l} /$ well $)$ at $25^{\circ} \mathrm{C}$ for $1 \mathrm{~h}$. The wells were washed as above and incubated with $1.2 \mu \mathrm{g} / \mathrm{ml}$ of a biotinylated secondary antibody in $0.1 \%$ BSA/PBS $(100 \mu \mathrm{l} /$ well $)$ at $25^{\circ} \mathrm{C}$ for $30 \mathrm{~min}$. Then, the wells were washed and incubated with $2 \mu \mathrm{g} / \mathrm{ml}$ of an alkali phosphatase-conjugated streptavidin in $0.1 \% \mathrm{BSA} /$ PBS $(100 \mu \mathrm{l} /$ well $)$ at $25^{\circ} \mathrm{C}$ for $30 \mathrm{~min}$. Finally, the wells were incubated with PNPP (Pierce) in cacodylate buffer, $\mathrm{pH} 9.2(100 \mu \mathrm{l} /$ well $)$ at $25^{\circ} \mathrm{C}$ for 5 minutes, and then OD $405 \mathrm{~nm}$ was read on a microplate reader. For the analysis of "post-binding" effects (i.e. dissociation of heparin-ligand complexes), $25 \mu \mathrm{l}$ of each heparin-binding factor was added to plates coated with heparin-BSA after blocking with $3 \%$ BSA. The plates were incubated at $25^{\circ} \mathrm{C}$ for 30 min to form the heparin-factor complex. The wells were washed as above and then incubated with $100 \mu \mathrm{l}$ of the enzyme reaction mixture as described above. After washing the wells, the amount of bound factor was determined with the antibody detection procedures described above. For the "pre-binding" study of FGF-1 binding to heparan sulfate-BSA, $1 \mathrm{mg} / \mathrm{ml}$ of heparan sulfate-BSA was coated on a 96-well plate $(100 \mu \mathrm{l} /$ well). Other procedures are the same as described above for the heparin-BSA assay. Repre- sentative data are shown from one of 2-3 independent experiments in all cases.

\section{Western blotting}

A purified FLAG-tagged HSulf-2 (10 ng) or concentrated MCF-7 CM $(10 \mu \mathrm{l})$ was separated by electrophoresis on a reducing SDS-7.5\% polyacrylamide gel (Bio-Rad), and blotted onto ProBlott ${ }^{\mathrm{TM}}$ membrane (Applied Biosystems, Foster City, CA). The membrane was blocked with 5\% skim milk/PBS-T for $1 \mathrm{~h}$ and then incubated overnight with an anti-HSulf-2 peptide antibody (see below) at a concentration of $1 \mu \mathrm{g} / \mathrm{ml}$ in $5 \%$ skim milk/PBS-T at $4{ }^{\circ} \mathrm{C}$. The membrane was washed and incubated with horseradish peroxidase-conjugated goat anti-rabbit IgG (Jackson ImmunoResearch Laboratories Inc, West Grove, PA) (0.2 $\mu \mathrm{g} / \mathrm{ml}$ ) for $1 \mathrm{~h}$. Bound antibodies were visualized with SuperSignal West Pico Chemiluminescent reagent (Pierce).

\section{Immunoprecipitation of HSulf-2 in MCF-7 CM}

A mixture of anti-HSulf-2 peptide antibodies, H2.1 (5 $\mu \mathrm{g})$ and H2.3 $(5 \mu \mathrm{g})$ [25], or a rabbit IgG $(10 \mu \mathrm{g}), 10 \mu \mathrm{l}$ of a $50 \%(\mathrm{v} / \mathrm{v})$ suspension of protein A-Sepharose (IPA400HC, RepliGen) and $100 \mu \mathrm{l}$ of 100-fold concentrated CM of MCF-7 cells were mixed in a total volume of $1 \mathrm{ml}$ with $150 \mathrm{mM} \mathrm{NaCl}$ and $50 \mathrm{mM}$ Tris- $\mathrm{HCl}, \mathrm{pH}$ 7.4. The mixture was rocked overnight at $4{ }^{\circ} \mathrm{C}$. The immunocomplexes bound to the protein A beads were removed by centrifugation. The "pre-binding" and "post-binding" ELISA activities remaining in the supernatant were assayed as described above.

\section{Endoglucosamine-6-sulfatase assay}

Endoglucosamine-6-sulfatase activity of rHSulf-2 and MCF-7 CM was determined by previously established procedures [15]. The standard reaction mixture contained 5 $\mu \mathrm{mol}$ of HEPES, pH7.8, $1 \mu \mathrm{mol}$ of $\mathrm{MgCl}_{2}, 5 \mu \mathrm{g}$ of porcine intestinal heparin (Sigma), and a purified FLAG-tagged HSulf- 2 or a 100 -fold concentrated MCF-7 CM in a total volume of $100 \mu \mathrm{l}$. The mixture was incubated at $37^{\circ} \mathrm{C}$. The reaction was stopped by heating at $100^{\circ} \mathrm{C}$ for $2 \mathrm{~min}$. The heparin was digested into disaccharides by a mix of heparinase I, heparinase II and heparinase III [15]. The disaccharides were then analyzed by HPLC on a Partisil10 SAX column (Whatman, Fairfield, NJ) [15]. The enzymatic activity was defined by calculating the increase in the moles of unsaturated disulfated disaccharide, $\operatorname{IdoA}(2 \mathrm{~S})-\mathrm{Glc}(\mathrm{NS})$, in the digested heparin.

\section{List of abbreviations used}

$\mathrm{CHO}$, Chinese hamster ovary, $\mathrm{CM}$, conditioned medium; ECM, extracellular matrix; FGF, fibroblast growth factor; GAG, glycosaminoglycan; HS, heparan sulfate; HSPG, heparan sulfate proteoglycan; HSulf-2, human Sulf-2; rHSulf-2, recombinant flag-tagged human Sulf-2; r $\Delta \mathrm{CCH}-$ 
Sulf-2, recombinant inactive mutant of human Sulf-2; SAGE, serial analysis of gene expression; SDF, stromal cell-derived factor; VEGF, vascular endothelial growth factor.

\section{Authors' contributions}

KU participated in the study design and coordination, performed and interpreted the studies, and drafted the manuscript. MM-T and $\mathrm{AB}$ participated in the studies of recombinant HSulfs and preparation of anti-HSulf antidodies. JL participated in ELISA studies. ML and JG participated in the studies with heparan sulfate-BSA. ZW participated in the study design. SDR participated in the design and coordination of the studies and edited the manuscript. All authors have read and approved the final manuscript.

\section{Acknowledgements}

This work was supported by National Institutes of Health (NIH) Grants ROI GM574II and R37 GM23547 (SDR), POI Al53 I 96 (ZW), a Mizutani Foundation Grant for Glycoscience (SDR), a UCSF Comprehensive Cancer Center Intramural Award from the Alexander and Margaret Stewart Trust (SDR). KU and MM-T are Research Fellows of the Japan Society for the Promotion of Science.

\section{References}

I. Bernfield M, Gotte M, Park PW, Reizes O, Fitzgerald ML, Lincecum J, Zako M: Functions of cell surface heparan sulfate proteoglycans. Annu Rev Biochem 1999, 68:729-777.

2. Esko JD, Lindahl U: Molecular diversity of heparan sulfate. J Clin Invest 200I, 108:169-173.

3. Ornitz DM: FGFs, heparan sulfate and FGFRs: complex interactions essential for development. Bioessays 2000, 22:108-1/2.

4. Nakato H, Kimata K: Heparan sulfate fine structure and specificity of proteoglycan functions. Biochim Biophys Acta 2002, 1573:312-318.

5. Esko JD, Selleck SB: Order out of chaos: assembly of ligand binding sites in heparan sulfate. Annu Rev Biochem 2002, 71:435-471.

6. Witt DP, Lander AD: Differential binding of chemokines to glycosaminoglycan subpopulations. Curr Biol 1994, 4:394-400.

7. Gallagher JT: Heparan sulfate: growth control with a restricted sequence menu. J Clin Invest 200I, 108:357-36I.

8. Lindahl U, Kusche-Gullberg M, Kjellen L: Regulated diversity of heparan sulfate. J Biol Chem 1998, 273:24979-24982.

9. Powell AK, Yates EA, Fernig DG, Turnbull JE: Interactions of heparin/heparan sulfate with proteins: appraisal of structural factors and experimental approaches. Glycobiology 2004, 14: I7R-30R.

10. Murphy KJ, Merry CL, Lyon M, Thompson JE, Roberts IS, Gallagher JT: A new model for the domain structure of heparan sulfate based on the novel specificity of K5 lyase. J Biol Chem 2004, 279:27239-27245

II. Jayson GC, Vives C, Paraskeva C, Schofield K, Coutts J, Fleetwood A, Gallagher JT: Coordinated modulation of the fibroblast growth factor dual receptor mechanism during transformation from human colon adenoma to carcinoma. Int J Cancer 1999, 82:298-304.

12. Brickman YG, Ford MD, Gallagher JT, Nurcombe V, Bartlett PF, Turnbull JE: Structural modification of fibroblast growth factorbinding heparan sulfate at a determinative stage of neural development. J Biol Chem 1998, 273:4350-4359.

13. Habuchi O: Diversity and functions of glycosaminoglycan sulfotransferases. Biochim Biophys Acta 2000, 1474: I I5-I27.

14. Dhoot GK, Gustafsson MK, Ai X, Sun W, Standiford DM, Emerson CPJ: Regulation of Wnt signaling and embryo patterning by an extracellular sulfatase. Science 200I, 293:1663-1666.
15. Morimoto-Tomita M, Uchimura K, Werb Z, Hemmerich S, Rosen SD: Cloning and characterization of two extracellular heparindegrading endosulfatases in mice and humans. J Biol Chem 2002, 277:49|75-49|85.

16. Ai X, Do AT, Lozynska O, Kusche-Gullberg M, Lindahl U, Emerson CPJ: QSulfI remodels the 6-O sulfation states of cell surface heparan sulfate proteoglycans to promote Wnt signaling. J Cell Biol 2003, 162:34I-35I.

17. Viviano BL, Paine-Saunders S, Gasiunas N, Gallagher J, Saunders S: Domain-specific modification of heparan sulfate by QsulfI modulates the binding of the bone morphogenetic protein antagonist Noggin. J Biol Chem 2004, 279:5604-56 I I.

18. Ohto T, Uchida H, Yamazaki H, Keino-Masu K, Matsui A, Masu M: Identification of a novel nonlysosomal sulphatase expressed in the floor plate, choroid plexus and cartilage. Genes Cells 2002, 7:173-185.

19. Lai J, Chien J, Staub J, Avula R, Greene EL, Matthews TA, Smith DI, Kaufmann SH, Roberts LR, Shridhar V: Loss of HSulf-I up-regulates heparin-binding growth factor signaling in cancer. J Biol Chem 2003, 278:23107-23II7.

20. Lai JP, Chien JR, Moser DR, Staub JK, Aderca I, Montoya DP, Matthews TA, Nagorney DM, Cunningham JM, Smith DI, Greene EL, Shridhar V, Roberts LR: hSulfI Sulfatase promotes apoptosis of hepatocellular cancer cells by decreasing heparin-binding growth factor signaling. Gastroenterology 2004, I 26:23|-248.

21. Lai JP, Chien J, Strome SE, Staub J, Montoya DP, Greene EL, Smith DI, Roberts LR, Shridhar V: HSulf-I modulates HGF-mediated tumor cell invasion and signaling in head and neck squamous carcinoma. Oncogene 2004, 23: | 439- | 447.

22. Wang S, Ai X, Freeman SD, Pownall ME, Lu Q, Kessler DS, Emerson CPJ: QSulfI, a heparan sulfate 6-O-endosulfatase, inhibits fibroblast growth factor signaling in mesoderm induction and angiogenesis. Proc Natl Acad Sci U S A 2004, 10 I:4833-4838.

23. Li J, Kleeff J, Abiatari I, Kayed H, Giese N, Felix K, Giese T, Buchler MW, Friess H: Enhanced levels of Hsulf-I interfere with heparin-binding growth factor signaling in pancreatic cancer. Mol Cancer 2005, 4:14.

24. Morimoto-Tomita M, Uchimura K, Rosen SD: Novel Extracellular Sulfatase: Potential Roles in Cancer. Trends in Glycoscience and Glycotechnology 2003, 15:159-164.

25. Morimoto-Tomita M, Uchimura K, Bistrup A, Lum DH, Egeblad M, Boudreau N, Werb Z, Rosen SD: Sulf-2, a proangiogenic heparan sulfate endosulfatase, is upregulated in breast cancer. Neoplasia 2005, 7:1001-1010.

26. Kamimura K, Fujise M, Villa F, Izumi S, Habuchi H, Kimata K, Nakato $\mathrm{H}$ : Drosophila heparan sulfate 6-O-sulfotransferase (dHS6ST) gene. Structure, expression, and function in the formation of the tracheal system. I Biol Chem 200I, 276: $17014-17021$.

27. Bink RJ, Habuchi H, Lele Z, Dolk E, Joore J, Rauch G], Geisler R, Wilson SW, den Hertog J, Kimata K, Zivkovic D: Heparan sulfate 6-osulfotransferase is essential for muscle development in zebrafish. J Biol Chem 2003, 278:3। II 8-3। I27.

28. Kreuger J, Salmivirta M, Sturiale L, Gimenez-Gallego G, Lindahl U: Sequence analysis of heparan sulfate epitopes with graded affinities for fibroblast growth factors I and 2. J Biol Chem 200 I, 276:30744-30752.

29. Ashikari-Hada S, Habuchi H, Kariya Y, Itoh N, Reddi AH, Kimata K: Characterization of growth factor-binding structures in heparin/heparan sulfate using an octasaccharide library. J Biol Chem 2004, 279: 12346-12354.

30. Feyzi E, Lustig F, Fager G, Spillmann D, Lindahl U, Salmivirta M: Characterization of heparin and heparan sulfate domains binding to the long splice variant of platelet-derived growth factor $A$ chain. J Biol Chem 1997, 272:55।8-5524.

31. Ono K, Hattori H, Takeshita S, Kurita A, Ishihara M: Structural features in heparin that interact with VEGFI65 and modulate its biological activity. Glycobiology 1999, 9:705-7।I.

32. Lyon M, Deakin JA, Mizuno K, Nakamura T, Gallagher JT: Interaction of hepatocyte growth factor with heparan sulfate. Elucidation of the major heparan sulfate structural determinants. J Biol Chem 1994, 269: I I 216-I I 223.

33. Parthasarathy N, Goldberg IJ, Sivaram P, Mulloy B, Flory DM, Wagner WD: Oligosaccharide sequences of endothelial cell surface heparan sulfate proteoglycan with affinity for lipoprotein lipase. J Biol Chem 1994, 269:22391-22396. 
34. Feyzi E, Trybala E, Bergstrom T, Lindahl U, Spillmann D: Structural requirement of heparan sulfate for interaction with herpes simplex virus type I virions and isolated glycoprotein C. J Biol Chem 1997, 272:24850-24857.

35. Wang L, Brown JR, Varki A, Esko JD: Heparin's anti-inflammatory effects require glucosamine 6-O-sulfation and are mediated by blockade of L- and P-selectins. J Clin Invest 2002, I 10:127-136.

36. Ishihara M: Structural requirements in heparin for binding and activation of FGF-I and FGF-4 are different from that for FGF-2. Glycobiology 1994, 4:817-824.

37. Turnbull JE, Fernig DG, Ke Y, Wilkinson MC, Gallagher JT: Identification of the basic fibroblast growth factor binding sequence in fibroblast heparan sulfate. J Biol Chem 1992, 267: I0337-1034I.

38. Saad OM, Ebel H, Uchimura K, Rosen SD, Bertozzi CR, Leary JA: Compositional profiling of heparin/heparan sulfate using mass spectrometry: assay for specificity of a novel extracellular human endosulfatase. Glycobiology 2005, 15:818-826.

39. Pye DA, Vives RR, Turnbull JE, Hyde P, Gallagher JT: Heparan sulfate oligosaccharides require 6-O-sulfation for promotion of basic fibroblast growth factor mitogenic activity. J Biol Chem 1998, 273:22936-22942.

40. Houck KA, Leung DW, Rowland AM, Winer J, Ferrara N: Dual regulation of vascular endothelial growth factor bioavailability by genetic and proteolytic mechanisms. J Biol Chem 1992, 267:2603।-26037.

4I. Bleul CC, Fuhlbrigge RC, Casasnovas JM, Aiuti A, Springer TA: A highly efficacious lymphocyte chemoattractant, stromal cellderived factor I (SDF-I). J Exp Med 1996, I84: I 101-II09.

42. Kucia M, Jankowski K, Reca R, Wysoczynski M, Bandura L, Allendorf DJ, Zhang J, Ratajczak J, Ratajczak MZ: CXCR4-SDF-I signalling, locomotion, chemotaxis and adhesion. J Mol Histol 2004, 35:233-245.

43. Christopherson KW, Hood AF, Travers JB, Ramsey H, Hromas RA Endothelial induction of the T-cell chemokine CCL2I in Tcell autoimmune diseases. Blood 2003, 101:801-806.

44. Elkin M, Ilan N, Ishai-Michaeli R, Friedmann Y, Papo O, Pecker I, Vlodavsky I: Heparanase as mediator of angiogenesis: mode of action. Faseb / 200I, I 5:166I-1663.

45. Bergers G, Brekken R, McMahon G, Vu TH, Itoh T, Tamaki K, Tanzawa K, Thorpe P, Itohara S, Werb Z, Hanahan D: Matrix metalloproteinase-9 triggers the angiogenic switch during carcinogenesis. Nat Cell Biol 2000, 2:737-744.

46. Vlodavsky I, Friedmann Y: Molecular properties and involvement of heparanase in cancer metastasis and angiogenesis. J Clin Invest 200I, 108:34I-347.

47. Goldshmidt O, Zcharia E, Abramovitch R, Metzger S, Aingorn H, Friedmann Y, Schirrmacher V, Mitrani E, Vlodavsky I: Cell surface expression and secretion of heparanase markedly promote tumor angiogenesis and metastasis. Proc Natl Acad Sci U S A 2002, 99: $10031-10036$.

48. Najjam S, Gibbs RV, Gordon MY, Rider CC: Characterization of human recombinant interleukin 2 binding to heparin and heparan sulfate using an ELISA approach. Cytokine 1997, 9:1013-1022.

Publish with Bio Med Central and every scientist can read your work free of charge

"BioMed Central will be the most significant development for disseminating the results of biomedical research in our lifetime. "

Sir Paul Nurse, Cancer Research UK

Your research papers will be:

- available free of charge to the entire biomedical community

- peer reviewed and published immediately upon acceptance

- cited in PubMed and archived on PubMed Central

- yours - you keep the copyright
BioMedcentral 